\title{
Hiperplasia gingival por ciclosporina: A propósito de un caso
}

\author{
Carlos Bahamondes $\mathrm{B}^{1,2 a}$, Jorge G odoy $0^{1, b}$. \\ Cyclosporine-induced gingival \\ hyperplasia: Report of one case
}

Gingival enlargement can be an adverse effect of ciclosporine A and nifedipine use. It has a high relapse rate if the drugs are not discontinued. There is a genetic predisposition to the development of this condition and dental biofilm can also play a role. We report a 64 years old male who received a renal allograft and was treated with cyclosporine and nifedipine. He required six surgical interventions for generalized gingival enlargement. After the sixth relapse, the patient was subjected to a periodontal treatment to eliminate the dental biofilm, which decreased the rate of recurrence of gingival enlargement (Rev Méd Chile 2007; 135: 370-74).

(Key words: Biofilm; Cyclosporine; Gingival hyperplasia)

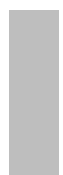

Recibido el 19 de diciembre, 2005. Aceptado el 17 de julio, 2006.

${ }^{1}$ Cátedra de Periodoncia, Universidad de Valparaíso. Servicio Odontológico Hospital Dr. Gustavo Fricke, Viña del Mar. ${ }^{2}$ Universidad Andrés Bello, sede Viña del Mar.

${ }^{a}$ Cirujano Dentista - Periodoncista

${ }^{b}$ Cirujano Dentista

$\mathrm{M}$ uchas de las enfermedades sistémicas y de las terapias farmacológicas indicadas en ellas, tienen repercusiones en la cavidad oral. Es así como algunos fármacos como anticonvulsivantes (fenitoína), inmunosupresores (ciclosporina A) y bloqueadores de canales de calcio (nifedipino, verapamil, diltiazem y valproato sódico) se vinculan a la aparición de agrandamientos gingivales. Algunos autores recomiendan cambiar el término hiperplasia por el de agrandamiento gingival, ya que el incremento en el tamaño del tejido es debido a un aumento en su estroma y no al número de sus células constituyentes ${ }^{1}$, término

Correspondencia a: Dr. Jorge Godoy O. Subida Carvallo 211, Playa Ancha - Valparaíso. Casilla: 178-V.

E mail: jlgodoyolave@vtr.net que ocuparemos para este trabajo. Se define como agrandamiento gingival al aumento exagerado y desfigurante del volumen de la encía, asociándose su aparición principalmente a fármacos ${ }^{2,3}$.

Se describe que $30 \%$ de los pacientes que toman ciclosporina A desarrollan agrandamiento gingival, con una alta tasa de recidiva, aumentando su prevalencia al doble al encontrarse junto a nifedipino ${ }^{4}$, no poseyendo una etiología única, sino una serie de factores asociados ${ }^{5,6}$. Si bien es aceptada su relación directa con fármacos y el factor genético, entre otros, el rol del biofilm bacteriano (placa dental) ha sido controvertido ${ }^{5-9}$.

La ciclosporina A es un potente inmunosupresor del grupo de inhibidores de la calcineurina, junto al tacrolimo, que actúa principalmente sobre el linfocito $\mathrm{T}$ por el bloqueo de la interleuquina 2. Indirectamente, altera la función monocitaria por la supresión de una variedad de linfoquinas del 
linfocito T como es el caso del interferón $\gamma$, factor inhibidor de los macrófagos y factor quimiotáctico de los macrófagos. Por ello, la producción de la interleuquina 1, por parte del monocito, se inhibe con un efecto no sólo en la inflamación, sino también en las células del tejido conectivo. Como algunos de sus efectos adversos se nombran nefrotoxicidad, hepatotoxicidad, neurotoxocidad, proliferación neoplásica linfocitaria y agrandamiento gingival ${ }^{10}$.

La determinación cierta de un mecanismo patogénico en el agrandamiento inducido por ciclosporina $\mathrm{A}$ ha sido incierto a lo largo de los años, no se ha podido determinar de forma cierta su mecanismo. Se asocia desde factores locales, como la presencia de biofilm bacteriano, hasta factores sistémicos y una predisposición genética. Se ha descrito que el metabolito OL-17 de la ciclosporina podría interactuar con cierta subpoblación fenotípicamente distinta del fibroblasto gingival, desencadenando en el aumento de la síntesis de proteínas y proliferación celular ${ }^{11}$. Estudios in vitro en fibroblastos humanos han ratificado una variedad de respuestas celulares individuales en su proliferación ${ }^{11}$. Esta heterogeneidad fibroblástica también afecta la actividad sobre los tejidos de las colagenasas y metaloproteinasas. Otra posible causa de la variabilidad de respuestas ante los pacientes expuestos a la ciclosporina A sería la expresión de cierto antígeno linfocitario humano (HLA-DR1), el cual presentaría un rol protector ante el desencadenamiento de agrandamientos gingivales, a diferencia del HLA-DR2, el cual aumentaría el riesgo de desencadenar dicha entidad patológica ${ }^{11}$. En el tejido conectivo in vitro la ciclosporina A provocaría un aumento de la matriz, glicoaminoglicanos no sulfatados y en la síntesis colágena, pero no en la síntesis de $\mathrm{ADN}$, con un aumento en el nivel de procolágeno tipo $\mathrm{I}^{11}$. Recientemente se ha asociado la proliferación fibroblástica y de los constituyentes de la matriz conectiva a factores de crecimiento como el factor de crecimiento B derivado de las plaquetas, sugiriendo además, que el macrófago cambiaría el fenotipo y la regulación de este factor, contribuyendo al agrandamiento gingival asociado a ciclosporina $\mathrm{A}^{11}$. La mayoría de los estudios sugiere una inhibición en el desarrollo y recurrencia del agrandamiento asociado a ciclosporina A al control del biofilm bacteria- no y reducción de la inflamación. Se sugiere que in vitro la ciclosporina A inhibe el efecto del lipopolisacárido (LPS), por lo que la concentración de LPS que resulta normalmente citotóxica a los fibroblastos causa una proliferación fibroblástica a causa de la ciclosporina. A pesar de estos resultados, algunos autores no han encontrado correlación entre la presencia de biofilm bacteriano e inflamación con el agrandamiento gingival inducido por ciclosporina ${ }^{12}$.

Por su parte, el nifedipino inhibe selectivamente flujo del ión calcio a través de la membrana de la célula del músculo cardiaco, describiéndose un agrandamiento gingival en solo 0,5\% de los pacientes que ingieren este fármaco ${ }^{12}$.

La presente publicación posee como objetivo describir un caso clínico de agrandamiento gingival severo asociado a ciclosporina A y nifedipino, su tratamiento y prevención de su recidiva mediante el control del biofilm bacteriano.

\section{CASO CLÍNICO}

Paciente JSL, sexo masculino, 64 años de edad, con antecedente de hipertensión y alcoholismo, comenzó diálisis por insuficiencia renal en junio de 1995 en el Hospital Dr. Gustavo Fricke. En enero de 1997 fue derivado a la especialidad de periodoncia del Servicio Odontológico, con el fin de tratar una periodontitis del adulto, de lo cual fue tratado y dado de alta el mismo año. En diciembre de 1998 fue reingresado a periodoncia por una inflamación gingival, encontrándose algunos focos de agrandamiento gingival localizados, de origen idiopático. En octubre de 2000 se volvió a diagnosticar gingivitis, condición que no fue bien resuelta durante su tratamiento.

En marzo de 2001 se le realizó un trasplante renal heterotópico, recibiendo ciclosporina A desde esa fecha. En agosto del mismo año se le diagnosticó un agrandamiento gingival asociado al consumo de fármacos (ciclosporina A y nifedipino) en dientes anterosuperiores (grupo II) y anteroinferiores (grupo V), practicándole cirugías periodontales en noviembre del mismo año (en ambos grupos dentarios), junio de 2002 (grupo II), noviembre del mismo año (grupo V), febrero, marzo y abril de 2003, todas en los dientes anterosuperiores. Si bien la cirugía gingival eliminó el tejido sobrante, la 
enfermedad recidivó constantemente. Durante este periodo fue atendido en la Facultad de Odontología de la Universidad de Valparaíso, siendo tratado periodontalmente sin una terapia quirúrgica. En diciembre de 2003, luego de seis intervenciones, el paciente recidivó en su enfermedad a menos de 7 meses de la última intervención, con un agrandamiento gingival severo generalizado, el cual provocó el ocultamiento de los dientes por parte de la encía, y su desplazamiento (Figura 1).

El paciente fue sometido a un tratamiento periodontal, enfocándose a uno de los factores etiológicos primarios del agrandamiento gingival asociado a fármacos, y frecuentemente olvidado, el biofilm bacteriano. La terapia quinúrgica fue retoma- da en diciembre de 2003 (grupo II), enero (dientes posteriores izquierdos) y marzo (dientes posteriores izquierdos e inferiores) de 2004. Al paciente se le tomó una biopsia, en la cual se apreciaba un epitelio pluriestratificado paraqueratinizado, delgado e irregular (Figura 2). Las crestas epiteliales se apreciaban profundamente en un tejido conectivo medianamente colagenizado, altamente vascularizado con numerosos vasos de pequeño calibre e invadido de células inflamatorias, mayoritariamente células plasmáticas y linfocitos (Figura 2).

Luego de la terapia, a 10 meses del tratamiento, el paciente presentó una leve recidiva en el molar superior izquierdo, realizándose la eliminación del tejido sobrante en enero de 2005 (Figura 3).

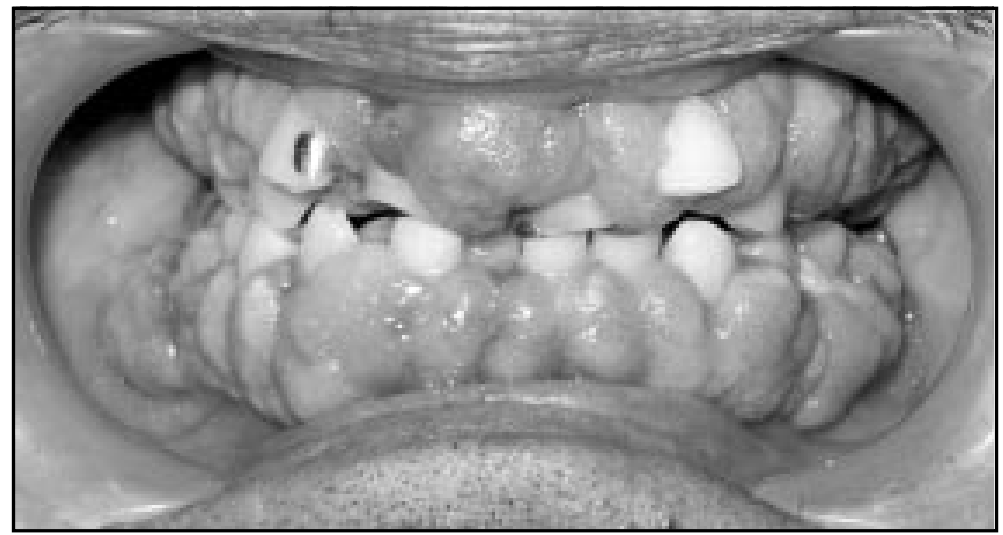

Figura 1. Agrandamiento gingival severo generalizado asociado a ciclosporina A.

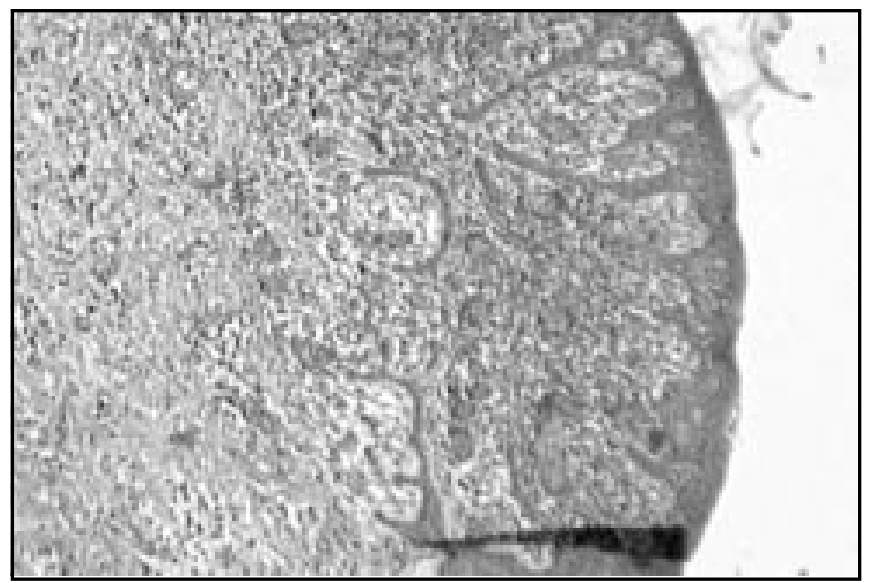

Figura 2. Corte histológico de agrandamiento gingival. 


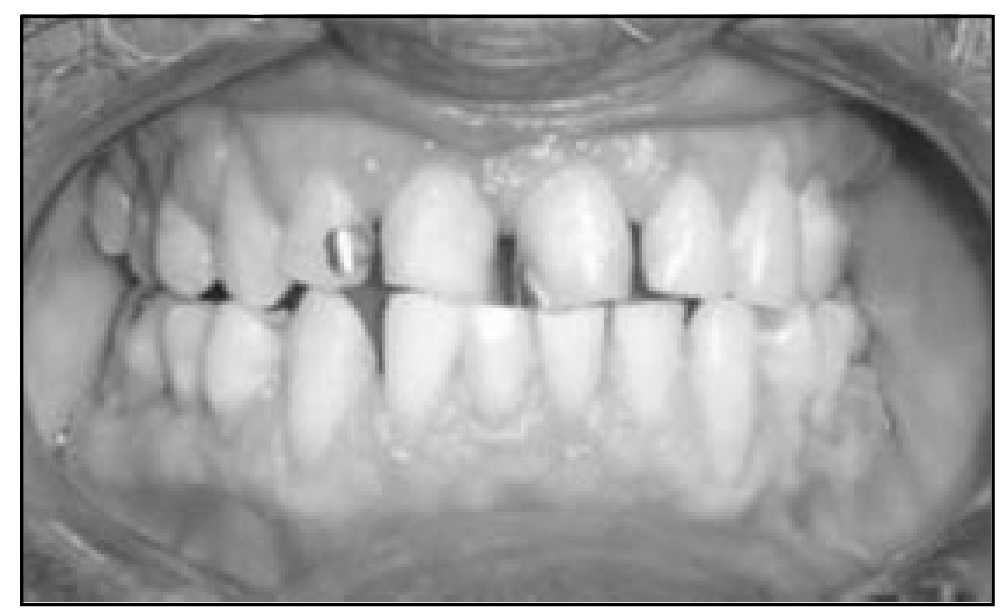

Figura 3. Estado del paciente a 7 meses del tratamiento periodontal etiológico-quirúrgico.

\section{DisCUSIÓN}

El evidente agrandamiento gingival poseía los signos clínicos habituales, aumento de volumen gingival indoloro, en forma de mora, con minúsculos lóbulos, color rosado pálido y resiliente. El sangrado gingival, no habitual en agrandamientos, nos indica la existencia de un componente inflamatorio anexo, originado por el biofilm bacteriano. El aumento de volumen gingival se observa en presencia de dientes, aunque se han descrito casos de agrandamientos en pacientes desdentados.

Histológicamente, se evidencia una marcada hiperplasia del tejido conectivo y epitelial. Se observa haces colágenos densos, un incremento en la cantidad de fibroblastos y de nuevos vasos sanguíneos junto a focos de células inflamatorias.

$\mathrm{Si}$ bien el paciente presentaba una alta acumulación de biofilm bacteriano por su deficiente técnica de higiene oral, el aumento gingival y la pérdida de sus contornos normales dificultan más la eliminación del biofilm. Se reeducó la técnica de cepillado, cambiando a la técnica de Bass, movimientos de vibración en $45^{\circ}$ hacia el surco gingival, y se le indicó un set de elementos de higiene oral, el cual constaba de cepillo de corte recto y filamentos blandos, seda dental con cera y cepillo interproximal cónico. El tratamiento periodontal, basado en el pulido radicular, se realizó para tratar la periodontitis de base. La terapia quirúrgica se enfocó a la eliminación del tejido gingival excesivo, con el fin de permitir una buena higienización del paciente y efectuar pulido radicular, para el tratamiento de la periodontitis.

El exhaustivo control del biofilm bacteriano en el tratamiento evitó la recidiva que venía presentando el paciente en su historia periodontal.

Se debe considerar que el paciente consume dos fármacos considerados en la etiología del agrandamiento gingival, lo cual quizás le entrega su alta severidad al cuadro.

\section{CONCLUSIONES}

Gracias a la evidencia mostrada, es claro el rol del biofilm bacteriano en la patogénesis del agradamiento gingival inducida por ciclosporina A.

Se sugiere realizar un saneamiento odontológico del paciente ante del trasplante de órganos e indicar otras alternativas de medicamentos que no induzcan al desarrollo de agrandamientos gingivales. 


\section{REFERENCIA}

1. Rostock M, Fry H, TurNeR J. Severe gingival overgrowth associated with ciclosporine therapy. J Periodontol 1986; 57: 294.

2. Carranza F, Hogan E. Agrandamiento gingival. En: Newman M, Takei H, Carranza F, ed. Periodontología clínica. México: McGraw-Hill interamericana editores, 2004; 297-315.

3. MARIOTTI A. Dental plaque-induced gingival diseases. Ann Periodontol 1999; 4: 7-17.

4. Thomason J, Seymor R, Eшis J. Risk for gingival overgrowth inediated with ciclosporin in the absences of calcium channel blockers. J Clin Periodontol 2005; 32: 273-9.

5. Seymour R, Thomason J, Eus J. The pathogenesis of drug-induced gingival overgrowth. J Clin $\mathrm{Pe}$ riodontol 1996; 23: 165-75.

6. Seymour R, Eus J, Thomason J. Risk factors for drug-induced gingival overgrowth. J Clin Periodontol 2000; 27: 217-23.

7. McGraw T, Lam S, Coates J. Cyclosporin-induced gingival overgrowth correlation with dental plaque scores, gingival scores, and cyclosporin levels in serum and saliva. Oral Surg, Oral Med, Oral Pathol 1987; 64: 293-7.

8. Seymour R, Smith D. The effect of a plaque control programme on the incidence and severity of cyclosporine-induced gingival changes. J Clin Periodontol 1991; 18: 107-10.

9. Somacarrera M, Hernández G, Acero J, Moskow B. Factors relating to the incidence and severity of cyclosporine-induced gingival overgrowth in transplant patients. A longitudinal study. J Periodontol 1994; 65: 671-5.

10. BARTOLD P. Cyclosporine and gingival overgrowth. J Oral Pathol 1987; 16: 463-8.

11. HaLmon W, Rossman J. The role of drugs in the pathogenesis of gingival overgrowth. Periodontol 2000 1999; 21: 176-96.

12. Seymor R, Smith D, Rogers S. The comparative effects of azathioprine and cyclosporine on some gingival health parameters of renal transplant patients. A longitudinal study. J Clin Periodontol 1987; 14: 610-13.

13. BaraK S, Engelberg I, Hiss Z. Gingival hyperplasia caused by nifedipine. Histopatological findings. J Periodontology 1996; 58: 639-42.

14. Daley T, Wysocki G, Day C. Clinical and pharmacologic correlations in cyclosporine-induced gingival hyperplasia. Oral Surg, Oral Med, Oral Pathol 1986; 62: 417-21.

15. VAN STEENBERGHe D. Enfermedades generales y peniodonto. En: Lindhe J, Karting T, Lang N, ed. Periodontología clínica e implantología odontológica. Madrid: Editorial Médica Panamericana 2000; 335-359.

\section{Agradecimientos}

Deseamos agradecer al Dr. Rodrigo Fuentes C, docente de la Cátedra de Patología y Diagnóstico Oral de la Universidad de Valparaíso por su aporte en este trabajo. 